\title{
A data processing system adapted to the special needs of the emergency laboratory
}

\author{
D NEUMEIER, * H SATOR, GE RINDFLEISCH, M KNEDEL \\ From the Institut für Klinische Chemie, Klinikum Großhadern, Ludwig-Maximilians-Universität München, \\ München, West Germany
}

SUMMARY A data processing system for the emergency laboratory was integrated in our clinical laboratory computer system, its prime objective being the service requirements of the laboratory. It included the possibility of simultaneous optical reading of request forms and on-line capturing, processing, and printing of laboratory test data. Priority request forms, which allow the clinician to specify the interval by which emergency test results must be available, are registered by an optical reader and arranged according to urgency by the computer. The production of worksheets is replaced by visual display of information required for accurate specimen analyses on a large colour TV screen. The individual processing status of all tests from as many as $\mathbf{3 0}$ request forms is displayed in a colour code. For process control the updated delay time for test performance is faded in. All reports are produced by direct machine transfer of verified test results. For security purposes all steps of sample processing (request, result, report) are recorded via line printers outside the emergency laboratory.

The capacity of the computer for managing sample and data processing reduces the work load for technicians. This results in a reduction of the turn-round time of tests. $95 \%$ of all requested tests are performed and reported within the requested time period and in emergencies, test results are available within 5-10 min. There has been no major breakdown of the system in over one year of use.

The number of emergency tests in clinical laboratories has increased. Now, in some laboratories $25 \%$ of all routine analyses are requested as emergencies. ${ }^{1}$ In spite of the impact for patient care, workload and internal laboratory organisation, reports about this important facet are scanty. ${ }^{1-8}$

Many factors contribute to excess use of the chemical laboratory. In the case of emergency tests, requests arise from the proportion of high-intensity care beds in large university hospitals, the advent of new parameters, medicolegal considerations, inadequate knowledge of test characteristics by the physician responsible for requesting, and intrinsic difficulties of centralised laboratories in handling nonroutine samples. Until recently, large capacity analysers have been inappropriate for processing single specimens with only a few tests. In addition the

*Present address: Dr D Neumeier, Institut für Klinische Chemie, Klinikum Großhadern, PO Box 701 260, D-8000 München 70, GFR.

Accepted for publication 7 October 1982. procedure of blood sampling early in the day with reporting of results later the same day is not suitable in many clinical situations. This increasing demand as well as organisational problems led to the establishment of special emergency laboratories in many hospitals. This laboratory performs all tests which are collected outwith fixed admission hours for routine specimens. An advantage of centralising the emergency service in a single laboratory is that it provides a pool of specially trained technical staff, and that the greater work load reduces costs per single test. An important aspect of "emergency tests" is that not all the results are really needed within a few minutes or hours as long as they are available sometime during the day. ${ }^{10}$ The turn-round times desired by clinicians vary between minutes and a few hours.

In a study of 53 laboratories in North America, Barnett et al ${ }^{11}$ points out the problems in dealing with priority requests. Many institutions have a priority system, but a surprising number improvise, without a definite plan. For tests labelled as "soon", "instantly", "immediate", "stat", "urgent" or 
"rush", the priorities are determined depending on the patient's condition, in which hospital area the request originated or by the type of test requested. Such inexact terminology prompted us in 1978 to provide boxes on the request form to mark definitive delay times, which inform the staff when the results are required at the clinical units. Simultaneously and independently of us Henderson' ${ }^{1}$ developed a similar request form for emergency tests. Our experience, however, shows that it is very difficult to control the workflow of specimens in a changing order of priority by means of a conventional laboratory daybook system. This is particularly so when the work load is heavy and then the processing usually follows the "first-in/first-out" rule.

In response to the increasing work load and the problem of request priorities we incorporated the emergency data handling into the computer system of our clinical laboratory. The modification of our system was completed by June 1981 . Since that time it has been in constant routine use. We describe the present system and highlight the special requirements of an emergency laboratory in system design.

\section{Functions and workload of the Institute of Clinical Chemistry}

The Institute of Clinical Chemistry incorporated in a newly built university hospital is a centralised laboratory for all routine pathology tests in haematology including haemostasis, clinical chemistry, endocrinology and protein chemistry. It provides facilities around the clock for 14 clinical departments with 1348 beds as well as outpatient services. One hundred and eighteen beds are intensive care beds.

Each year over 530000 specimens with approximately $2 \cdot 8$ million requested tests and a workload of nearly 4.0 million analyses are performed. Within the emergency laboratory the daily workload varies between 350 and 500 requests with 2000 tests performed. This includes all tests out of routine admission hours $(0730-0900 \mathrm{~h})$ but excludes all the specimens of outpatients and the routine monitoring of blood glucose level. All specimens are sent directly from the clinical units to the laboratory by a dedicated pneumatic tube system.

Since June 1980 a new central clinical laboratory computer system assists in specimen processing and in handling of the data in all laboratories except the emergency laboratory. This new developed system is based on the experiences with an older data processing system (Siemens 305/SILAB) ${ }^{12}$ used from 1974 to 1980.
Design objectives of the emergency laboratory data processing system

The data processing system for the emergency laboratory was designed as part of the central clinical laboratory computer system but with the requirements of the emergency service as its prime objective. It includes optical reading of request forms with simultaneous capture, processing and printing of laboratory test data. The system is designed to facilitate smooth workflow and to reduce turnaround time. Emphasis is placed on the ability of the computer to manage sample processing in order of priority.

A data processing system in operation for $24 \mathrm{~h}$ must give maximum flexibility and protection from computer breakdown to be accepted by the laboratory technical staff. To provide this the emergency version of our clinical laboratory computer system was tailored to the needs of this laboratory and was designed so that:

(a) at any time the current status of sample processing is clearly obvious. Worksheets and resultlistings are replaced by display of all requisite information on a large colour TV monitor. The status of all tests from as many as $\mathbf{3 0}$ separate request forms is displayed in a colour code. From top to bottom the request forms are updated by the computer in a decreasing order of priority, not in the serial sequence of acquisition;

(b) on-line capture of patient identification data (PID) and nearly all of test result data is possible;

(c) specimens can be analysed in any sequence;

(d) no restraints are imposed on the order in which the work on each specimen is performed for the input of PID and the various test results are independent of each other;

(e) the laboratory technical staff can correct any test result;

(f) comments could, when necessary, replace or supplement test results in the final report document;

(g) all test results have to be validated by the laboratory technical staff. As far as possible they are assisted by the computer - for example, it checks for life-incompatible test results;

(h) each validated test result can be made available to the physician at any time, if necessary, as an incomplete report; $;$ a visual display unit is used to provide the laboratory technical staff all upto-the-minute information and all requisite data (demographic and test related data, all or selected updated previous results). At any time all relevant data up to the most recent, from all 
parts of the institute are available on this and all other VDUs in the system in order to answer telephone inquiries; the system is operated through a "menu" structure organised by a master program, which is executed automatically when a VDU is logged to the system. The master program then displays a list of options at the terminal. The speed of filing and retrieval is not reduced to such an extent as to render this impractical since multiple copies of specified programs can be active at the same time;

(i) in addition, worksheets are continuously generated by request form and result-listings generated by test result are produced near to but outside the laboratory. They provide a safety factor to ensure that no data already in the system are lost if the laboratory computer system breaks down. It should be emphasised that the worksheets are not used as a means of laboratory specimen management and that they do not impose any constraints on the laboratory technical staff. Indeed, the system allows processing and operation without any worksheets being printed at all.

\section{Hardware}

The computers used are two Siemens R-30 with $256 \mathrm{~K}$ words each and adequate external storage on two drums and four disc-drives. The peripheral units needed for the system are one semigraphic colour display unit, one VDU for communication with the system, one printer with 200 lines/min and five printers with 140 characters per second in the laboratory. In addition there are 22 printers distributed throughout the hospital. As interfaces, which are necessary to convert the output from analysers into a form suitable for input into the computer units of the SILAB system (Siemens AG, Munich) are used. ${ }^{12}$

\section{Software}

The emergency computer system is integrated as part of the central laboratory computer system. For the past two years this modular structured system serves all sections of the laboratory. ${ }^{13}$ To reach a high level of availability all application programs have been written in assembler language by the staff of the institute. The software allows, that the two central units operate in a master-slave mode - that is, one unit processes all data, while the other secures all important results and information.

\section{Processing of data}

The flow diagram (Fig. 1) demonstrates the main sequence of events.

\section{Request form}

We developed a computer readable request form for emergency tests (Fig. 2), which is in keeping with all other routine request forms of the institute but with the special requirements of the emergency laboratory in mind. On the front of the request form from top to bottom there have to be marked: the patient identification number (hospital number of the patient) which is unique for the period of hospitalisation; the ward code and the time the specimen was drawn; space follows for the clinical indication of the emergency

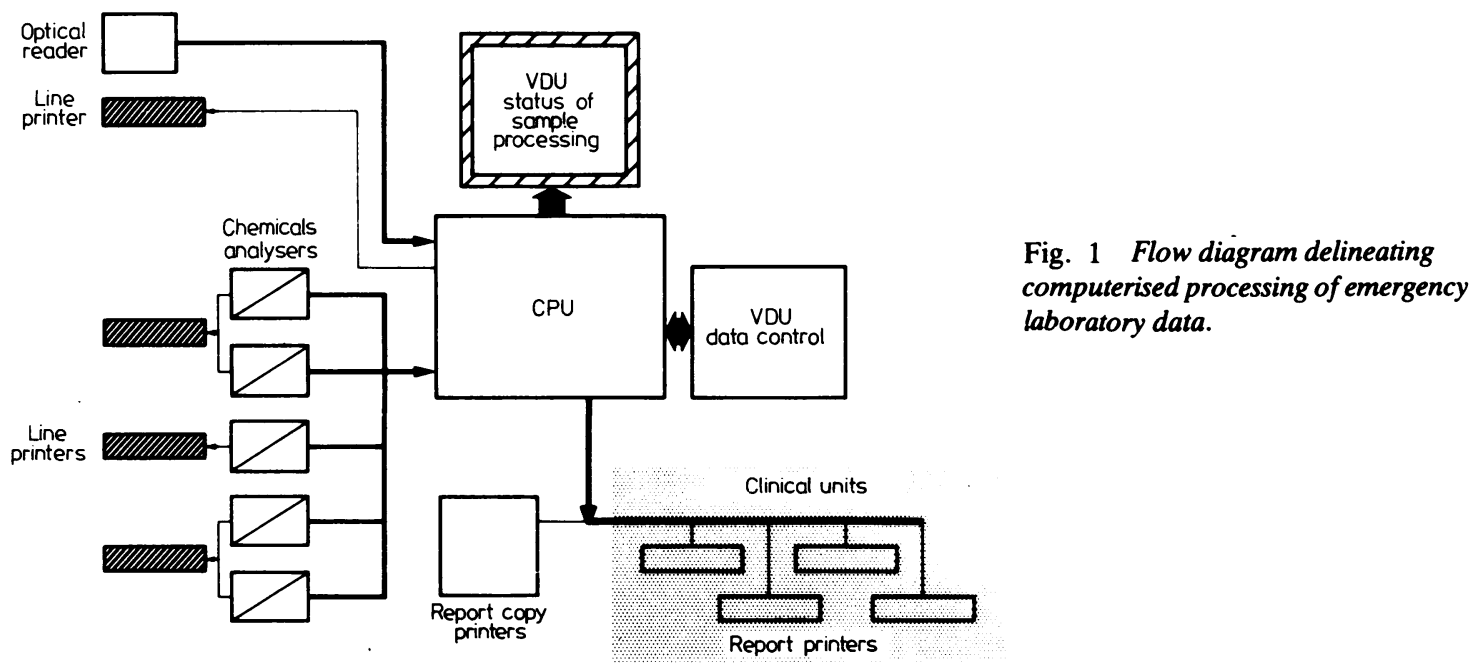

Fig. 1 Flow diagram delineating computerised processing of emergency laboratory data. 

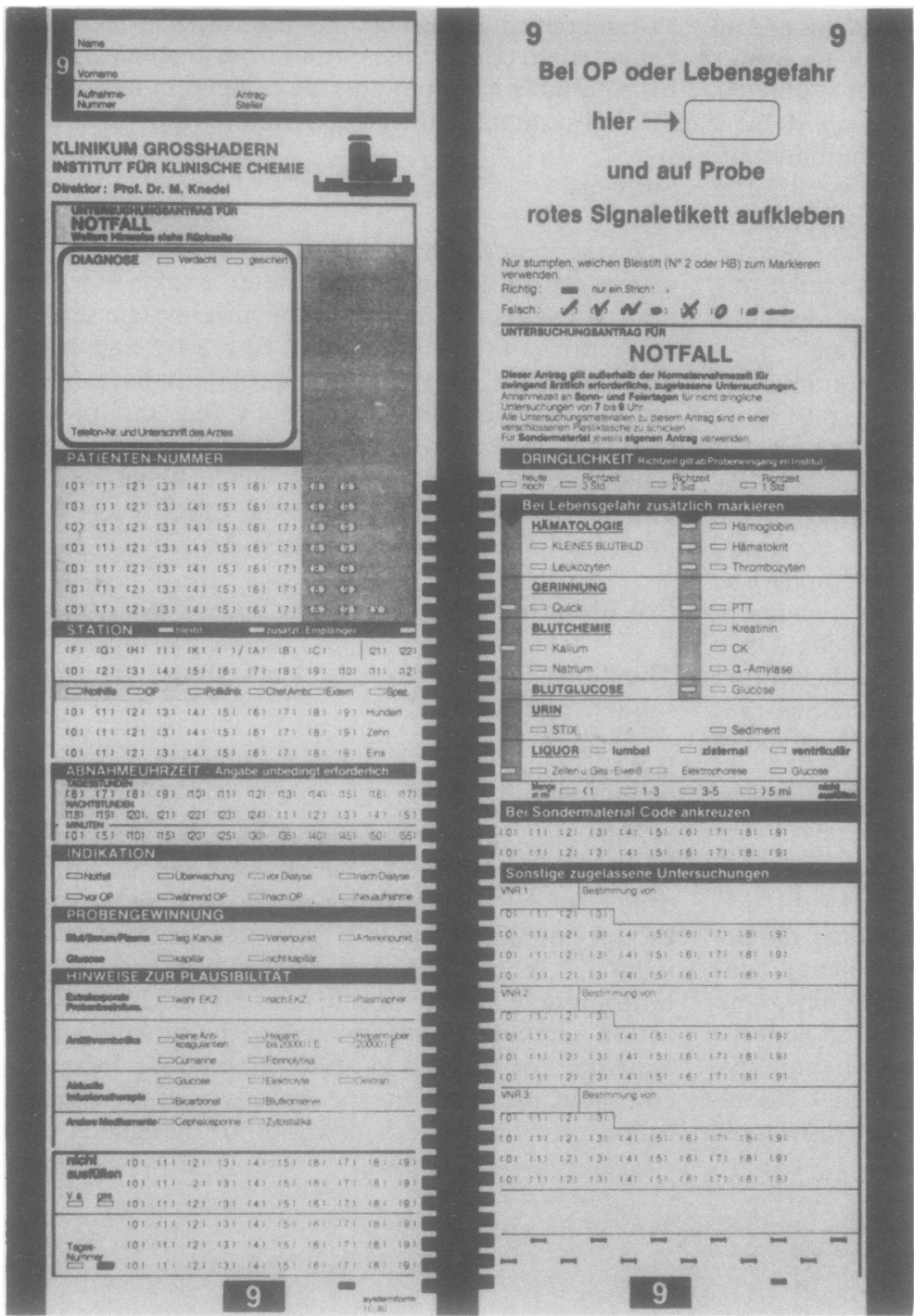

Fig. 2 Request form for the emergency laboratory: Front side (left) from top to bottom, Patient identification number, ward code, time when specimen was drawn, indication for non-routine investigations and additional clinical information. Reverse side (right) from top to bottom; boxes for the specific delay time, frequently performed tests (i.e., leucocyte count) and test code numbers of infrequently performed tests.

investigation, for clinical information relevant to the analysis itself and for the interpretation of the test results. At the bottom of the form fields are provided for the laboratory accession number.

When a specimen arrives at the laboratory the container or the containers and the accompanying test request form are given a five digit laboratory accession number. Self-adhesive labels are pre-printed for the identification of specimens. The first two digits of the accession number represent the day of the month and the last three start daily at 001 and are increased by one for each succeeding request form. This easily understood number is unique in any month and links patient identification data, sample collection time and test results. The computer is designed for up to
700 emergency request forms each day but could be expanded if necessary.

The back of the request form is reserved for indicating tests to be performed on the specimens. Those frequently performed are tabled and are requested by a single mark in the appropriate box; those infrequently requested are indicated by a four digit code number. The codes are specified in a directory issued to all medical and nursing staff. This list is updated regularly with the addition of new tests or discarding those found inadequate. On the first line of the back of the form, the requesting physician indicates the specific delay by which he should have the report of the emergency test results. This time interval, varying from one hour to sometime during 
the day, allows the clinician to discriminate between situations requiring immediate or delayed test performance. Single tests can be additionally flagged in an emergency or during a surgical operation, if test results indicate the need for immediate treatment of the patient. The signal induces the interruption of all other emergency services and the immediate performance of the flagged test.

\section{ENTRY OF THE DATA OF THE REQUEST FORM Real-time control}

All information on the request form is entered into the laboratory computer by a compact optical reader developed by our technical staff. ${ }^{14}$ Data on both sides of the request form are read simultaneously. In the event that a request form has not been read properly the readers display up to fifteen error codes. This allows real-time control of the data entry so that errors can be corrected at once. When the identification data for a new patient are missing, these data are recalled from the central hospital computer. In rare conditions of urgency, patient's name and forename can be entered into the computer via the VDU in the emergency laboratory.

\section{Processing control on the TV screen}

After reading the request form all data relevant for test performance are displayed on a large central colour TV screen. The request forms are continuously updated by the computer in a decreasing order of urgency according to the physician-indicated delay times and displayed like the presentation of the flying schedule at an airport. Each request form occupies one horizontal line and the ten most frequently requested tests are displayed in reserved columns. The information given on the screen for each request form is: accession number, remaining delay time for test performance and requested test symbolised by red rectangles in the respective columns. Tests performed infrequently are indicated by a red underlaid three-character code in the remaining fields. Flashing test symbols emphasise the highest priority of flagged tests. For process control the remaining delay time of test performance is updated by the computer every five minutes. This graphic presentation of all information required for priority controlled specimen analyses is generated continuously by each new request form. On the screen up to 30 acquisition numbers are displayed. In addition to these the number of request forms not outlined on the screen is faded in on the bottom.

The visual display allows the analytical procedure to start after batching of samples without any delay caused by worksheet printing. The samples can be analysed immediately after entering the accession number (see below) even before the information on the request sheet is input. In the few cases when a test-oriented worksheet is required to make up an assay batch listing can easily be triggered via entering the test code number by the technician.

\section{Additional information supplied by the computer system}

Provision has been made to have access to all patient data, which might be important for performing a test. By entering the laboratory accession number of the specimen or the patient identification number on a visual display unit pertinent data are displayed on the screen. This information includes name, sex, age, clinical unit, first day of hospitalisation, the clinical details marked on the request sheet including indication, diagnosis, therapeutic procedures influencing test or interpretation and the result and date of previous tests if any are on file. This information helps technical staff to prepare the specimen adequately and to monitor test performance.

By entering the patient identification number in a "historical" data file the cumulative results of all previous laboratory tests are obtained. Comprehensive computer-based cumulative filing according to test code number, date or the pathological character of results is possible as well. These disc file searches are not time consuming and do not retrench the "realtime" nature of the system.

\section{Data protection}

For security purposes a paper worksheet is printed outside the emergency laboratory. This worksheet generated continuously per laboratory accession number includes all the above specified "worksheettype" data. The list can be used when the central colour TV screen does not operate.

\section{TEST DATA CAPTURE}

On-line test data

The basic devices currently in use in the emergency laboratory include two Coulter Counters S, two flame photometers, two photometers, one atomic absorption photometer and two automated chemical analysers (ACA, DuPont) (Fig. 3). This nearly duplicated analytical equipment allows the immediate performance of laboratory tests in situations when a single analyser does not work. The laboratory computer receives on-line all the results generated by these analysers together with the associated sample accession number, which is entered into the computer via keyboards at the analysers or via the patient identification card (ACA, DuPont) before or concurrent with the entry of results. At both Coulter Counters $S$ the analytical results, the accession number and the patient identification number are merged and displayed together with the patient 


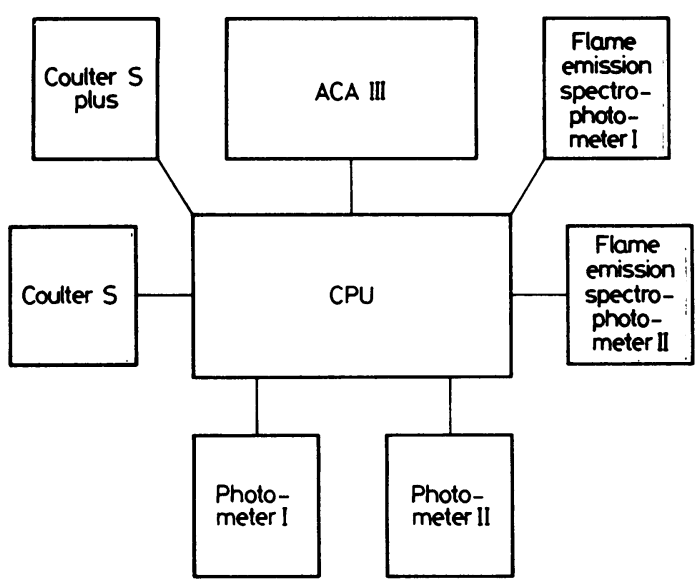

Fig. 3 On-line analysers of the emergency laboratory.

identity data and information about the previous test results on a small associated VDU screen. Values are flagged to highlight statistically abnormal and analytically invalid results that is, outside the measuring range, whole blood control sample outside the preset range. These methods, direct monitoring of results and computer-assisted quality control at the time of analysis, allow reduction of the sample processing time and technical staff do not have to wait for a hard print copy.

The photometers linked on-line by microprocessor interfaces have digital displays incorporated in the front panel. Test data transfer is initiated, when the "data" key is pressed. The laboratory data processing system provides an immediate printout of analytically doubtful results outside given limits, for example, quality control range, diluting limit.

\section{Manual test data}

The procedures for the miscellaneous manual tests such as coagulation tests, microscopic urine examination or cell counts in spinal fluid differs slightly from that of on-line tests. Here the results as well as the associated accession number are entered through a keyboard. For microscopic urine examination the keyboards used have keys coded for 16 various urine ingredients. The results of the coagulation tests measured in seconds or as a percentage of normal are entered directly. In addition, the keyboards are used for the correction of a test result and for the input of four digit comment codes representing a variety of reasons which may either exclude test performance or affect the result of a given test. An example of the first is the comment "clotted." This type of comment substitutes for a test result, whereas the comment "lipaemic" does not inhibit the input of a test result.

\section{Processing control on the colour TV screen}

On the colour TV screen the red rectangle symbolising the status of a requested test changes to yellow after entry of a computer-controlled test result in the result file. Thus every technologist within the rota has an immediate and continuously updated information of the processing status of all actual request forms.

\section{Data protection}

All analytical results entered into the computer are printed simultaneously with the associated accession number in a condensed form by line-printers outside the emergency laboratory. These intralaboratory result copies ensure that in the cases of a major failure in the data processing equipment only the most recently transferred data will be lost.

\section{DATA VALIDATION}

The computer controlled analytical data cannot be printed on patient reports until they have been reviewed and validated by the laboratory technical staff. The program used for preanalytical patient information provides also facilities to display the analytical results merged with requisite patient details on a VDU screen. Validated results are flagged by entering the single-character code $F$ for "free." This comment allocates the test results to the report printing program. When the laboratory staff, however, enters the comment $S$ (Sperren), the data are retained only in the raw data file. Additionally provisions are made to override the computer checks. The option $E$ (Entsperren) for "additionally controlled" enables the laboratory staff to verify a result, which has previously been blocked by the computerfor example, manually controlled results outside the measuring range of the Coulter S. For normal use test data validation is performed according to the accession number. But all these options can also be used in the result files of the single tests. When this way is chosen, the results of a single analytical method or a group of tests are displayed in the order in which the samples have been analysed. This type of data validation is advantageous if a set of results after batching of specimens is available.

\section{Process control on the TV screen}

All patients with result data for all tests requested are identified by a yellow underlaid accession number in the first column of the TV graph. This functions as an additional marker for the technical staff to validate results of completed tests. On the colour TV screen a validated test result is symbolised by a change of the colour code to green.

\section{REPORTS}

The data reporting mechanisms of an emergency 


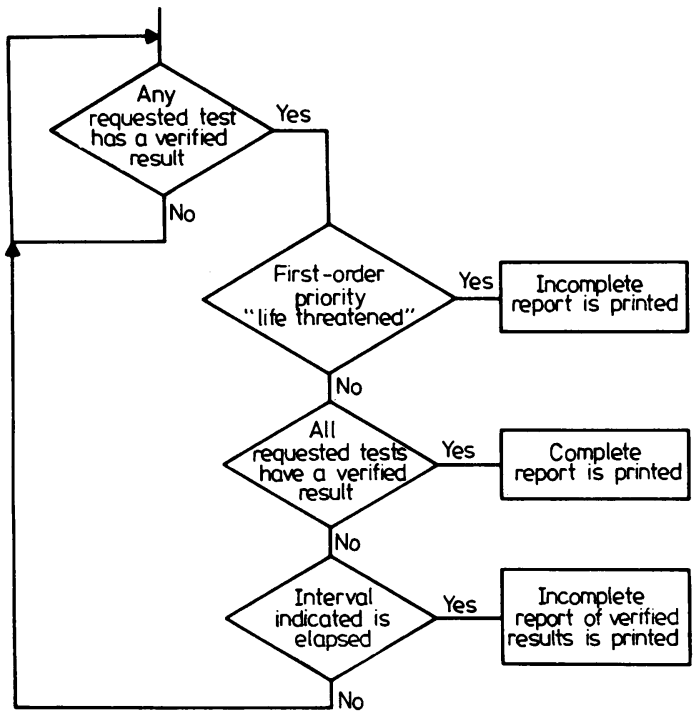

Fig. 4 Flow diagram showing the mechanisms of report printing.

laboratory computer system are pivotal to make results rapidly and reliably available to the physician. So as to impose no restrictions on diagnosis and treatment we developed reporting systems which cater for the variety of clinical requirements especially those of an emergency-(Fig. 4).

As outlined no report can be printed until each result has been verified, so that there is no time lag, the system allows printing of verified results automatically, when (a) a test is requested on first-order priority "lifethreatened." Immediately after verification of the test result an incomplete report is printed;

(b) all requested tests have a verified result. A complete final rush report is printed;

(c) the time interval indicated by the clinician on the report form is elapsed. In this case an incomplete report including all results verified at this moment is printed.

These mechanisms ensure that no restrictions are placed on reporting other than those of the analytical and verifying procedures. Additionally it is also possible to omit these mechanisms and to print either previously reported or incomplete reports at any time by typing in the appropriate code including the specimen accession number on any VDU. Routinely reports are printed once, but a supplementary report is also printed if the previous report was incomplete.

In addition to the test results and the patient identification data, the report (Fig. 5) contains other information of interest, which includes the times when the specimen was drawn, when the specimen arrived in the laboratory and when the report was printed, the correct address of destination and, finally, any comments about the state of the specimen. The essential information for the physician is repeated in an abbreviated form on a narrow tear-off strip of the report form. This self-adhesive strip can be fixed in the patient's chart.

The major part of all rush reports is printed directly via line printers at various sites throughout the hospital including all intensive care units, the anterooms of the operating theatres, and in the ambulatories. Only rush reports destined for general wards are printed

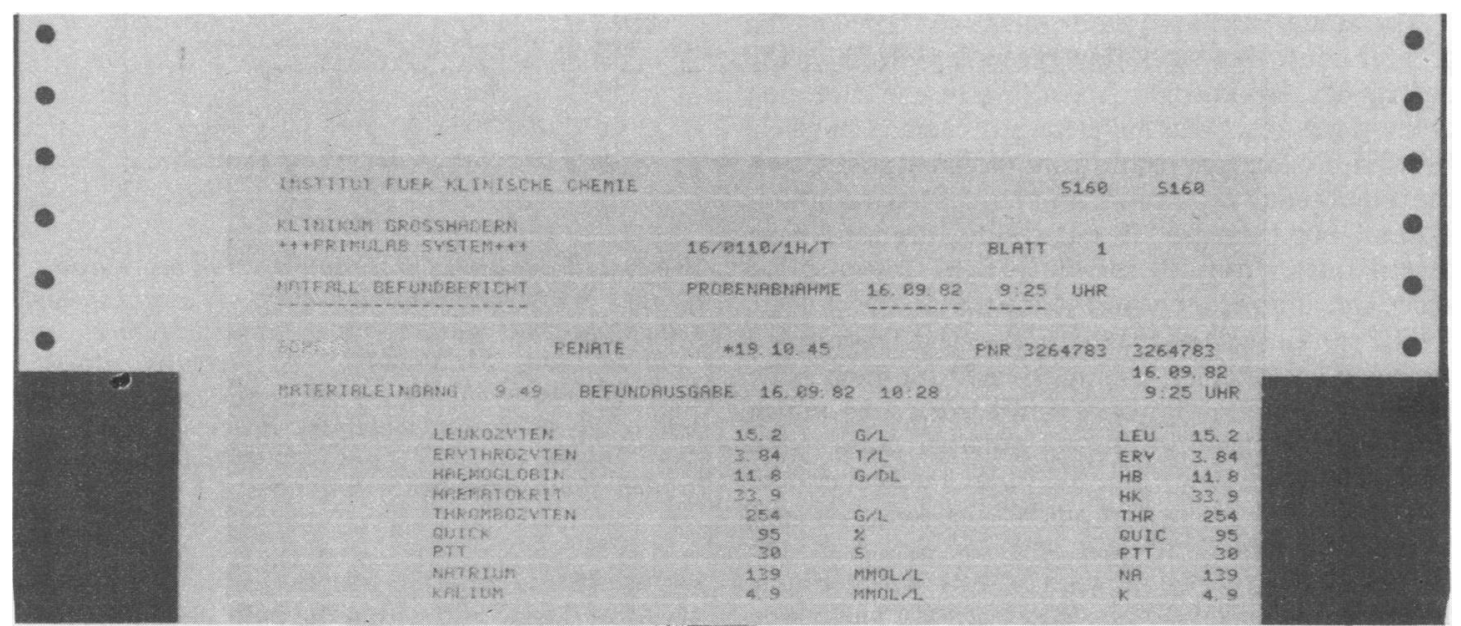

Fig. 5 Report form of the emergency laboratory. The lilac report form is fixed on top at a fan-fold transport paper. The test results, the patient identification number and the time when specimen was drawn are repeated in an abbreviated form on an adhesive tear-off strip at the right side. 
within the laboratory and are despatched to the wards via a pneumatic tube system. When a printer on the wards breaks down, all corresponding printing operations are performed in the laboratory until the printer is in operation again. As a general principle results previously not printed are never transmitted verbally because errors might be lethal and therefore all rush reports are produced by direct machine transfer.

A $22.5 \mathrm{~cm} \times 15 \mathrm{~cm}$ lilac paper sheet serves as report form. These sheets are fixed only on top slightly overlapping on a $29 \cdot 15 \mathrm{~cm}$ wide fan-fold transport paper. Single rush reports just printed can easily be torn off from the transport paper without handling the skipping device of the line printer, thus eliminating possible breakdowns caused by untrained personnel on the wards. For security reasons a condensed replica of printed final reports is produced continuously within the laboratory.

\section{Benefits of the system}

The emergency laboratory computer system has been in use for over two years. Except for occasional hardware problems affecting only parts of the system, there was no major breakdown. The laboratory staff found it easy to use after a short training period. The codes used for program handling and verification of results are simple and easy to memorise. The system has changed the type of work in the emergency laboratory considerably. The clerical tasks of entering specimen details into a reception book, transcribing results on both the laboratory day-book and on report forms, have all disappeared. The major benefit for the staff lies in the continual awareness of the processing status of all specimens present.

The actual workload is obvious at any time and the greater control of work flow places less stress on the emergency laboratory. According to the indicated delay times tests may be arranged in small batches. Further advantages result from the incorporation of the emergency laboratory in the central computer system. For example, all test results, even the most recent ones, from all sections of the Institute are accessible immediately and at any time.

The response from the medical staff in the hospital has been favourable. A major benefit for them is the reduction in the laboratory's turn-around time, which is achieved by the reporting of results according to the indicated delay time (Fig. 6). In an emergency, the results of test requested under this criterion are reported within 5-10 min after accession of the specimen. Ninety-one per cent of tests with one hour delay are reported within this interval. Thirty-five minutes after accession the final report of one half of these patients is printed or ready for despatch to the

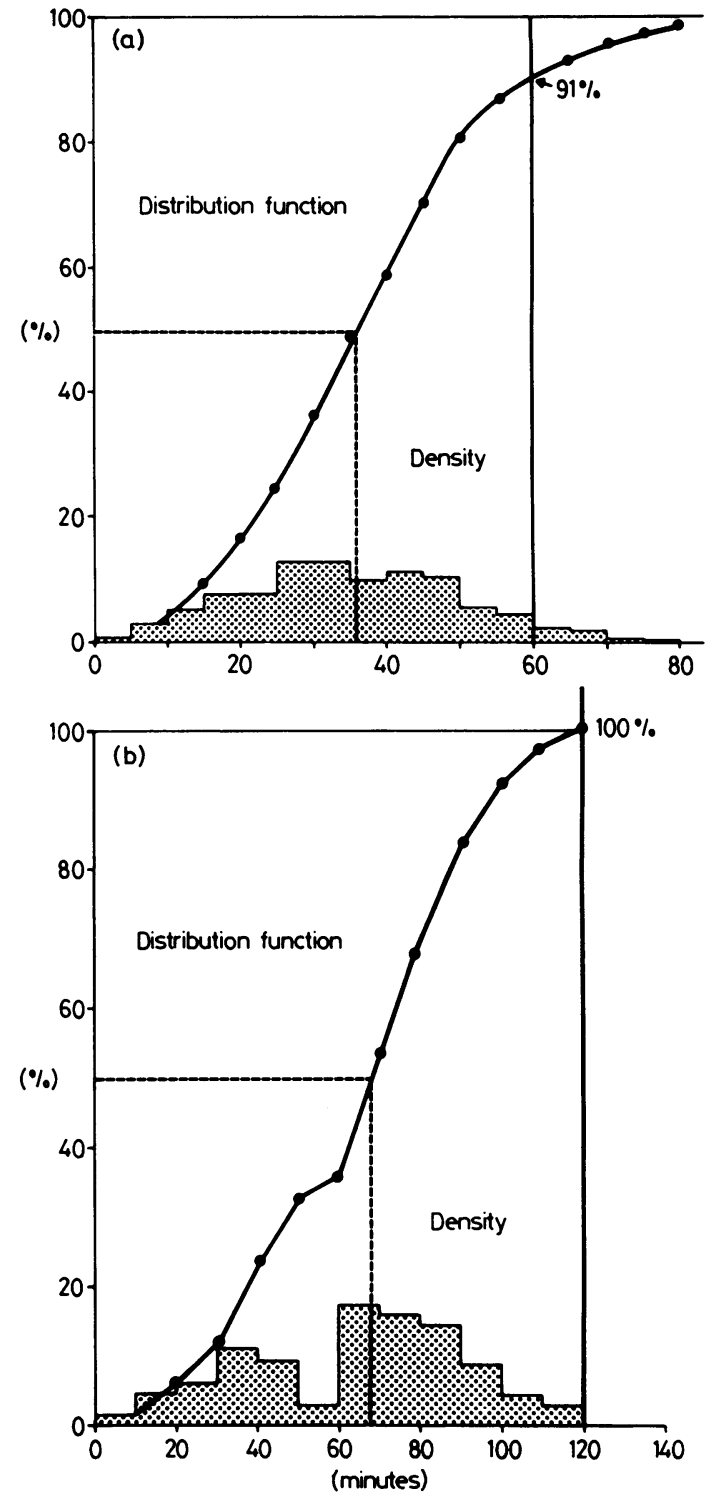

Fig. 6 Histograms of processing intervals between the acceptance of a specimen in the emergency laboratory and print of the final report. Above: indicated delay time

"1 hour" ( $n=1583)$. For $91 \%$ of all specimens the final report is printed within the indicated delay time. After $36 \mathrm{~min}$ $50 \%$ of all final reports are printed. Below: indicated delay time " 2 hours" $(n=237)$. For all specimens the final report is printed within the indicated delay time.

wards. Tests requested with two or more hours delay are always reported within the indicated interval.

The time delay boxes on the request form, however, have created some problems for the laboratory 
as the clinical unit's personnel sometimes lacks knowledge of how urgently a test result has to be available. Nearly two-thirds of all tests are requested with a one hour delay. It is in our own interest to reduce this percentage by continuous communication with the medical house-staff so there is best use of the emergency request forms. Another advantage from the user's point of view is the clear presentation of results, the better format of the printed reports and the ease with which telephone enquiries about previous results can be answered.

Whether the basic concept of an emergency laboratory data processing system as described, is generally applicable to other hospitals may be debated. However, the mechanisation of tests in the emergency laboratory and computerised data handling, provide better controlled reports more readily for the clinicians and will improve care at the bedside of the critically ill.

We would like to thank Dr Ch Pietrzyk for his help during the preparation of this paper and Miss $\mathrm{S}$ Hoffmann and Mrs I Wolfrum for typing this manuscript.

\section{References}

' Henderson AR. The priority request form - A method for improving communication between the physician and the Emergency Clinical Biochemistry Laboratory. J Clin Pathol 1979;32:97-9.

${ }^{2}$ Landon J, Sanders P, Peppiatt R, Clayton B, Jenkins P, Cotgrove I. Emergency chemical pathology service in central London. Lancet 1971;ii:480-2.

${ }^{3}$ Fèrard PG, Klumpp T, Ragagnin M, Metzger G, Mètais P. Description d'un systeme informatique dans un laboratoire d'analyses biologiques d'urgence. J Clin Chem Clin Biochem 1980;18:39-48.

${ }^{4}$ Prellwitz W, Schuster HP, Suter P, Linderer Th, Schlichting K. Das Instrumentarium der Intensivstation - Stoffwechselüberwachung (Basisprogramm, Lactatanalyse, Osmometrie, Onkometrie). Deutsch Med Wochenschr 1980;105:588-90.

5 Wiener K. Pathology measurements closer to the patient? J Clin Pathol 1980;33:857-63.

- Hannak D, Kattermann R. Notfall-Diagnostik - Notfall-Labor Folge 1: Kriterien des Notfall-Labors, Vorschläge für ein interdisziplinäres Basisprogramm und fachbezogene Zusatzprogramme. Fortschr Med 1981;99:57-61.

Notfall-Diagnostik - Notfall-Labor Folge 2: Zuordnung des Notfall-Labors, Organisation, Methoden und Geräte. Fortschr Med 1981;99:140-4.

7 Weil MH, Michaels S, Puri VK, Carlson RW. The Stat laboratory - facilitating blood gas and biochemical measurements for the critically ill and injured. Am J Clin Pathol 1981;76:34-42.

8 Wiener F, Weil MH, Carlson RW. Computer systems for facilitating management of the critically ill. Comput Biol Med 1982; 12:1-15.

9 Connely D, Steele B. Laboratory utilization - Problems and solutions (Editorial). Arch Pathol Lab Med 1980;104:59-62.

10 Murphy JM, Penberthy LA, Fraser CG. The clinical view of turnaround times for stat tests. Am J Clin Pathol 1979;70:885.

" Barnett RN, McIver DD, Gorton WL. The medical usefulness of stat tests. Am J Clin Pathol 1978;69:520-4.

12 Knedel M. Datenverarbeitung im Klinisch-Chemischen Institut am Städtischen Krankenhaus München-Harlaching - Ein System im Aufbau. Siemens Druckschrift Nr MC 50/1016.

13 Knedel M, Neumeier D, Vogt W, eds. Datenverarbeitung in der Klinischen Chemie - 10 Jahre Erfahrungen. GIT-Verlag Ernst Giebler: Darmstadt, 1983.

14 Killian K. Verarbeitung von klinisch-chemischen MeBwerten in redundanten Systemen durch externe und interne Variation von Programmstruktur und Messvorgang. In: Wagner G, Köhler CO, eds. Interaktive Datenverarbeitung in der Medizin Stuttgart - New York: Schattauer-Verlag FK, 1976:178-87.

Requests for reprints to: Dr D Neumeier, Institut für Klinische Chemie, Klinikum Broßhadern, PO Box 701260 , D-8000 München 70, GFR. 